\title{
Patient Satisfaction With Postmastectomy Breast Reconstruction
}

\author{
A Comparison of Saline and Silicone Implants
}

Colleen M. McCarthy, MD, MSㄱ; Anne F. Klassen, DPhil'2; Stefan J. Cano, PhD³; Amie Scott, BSc';

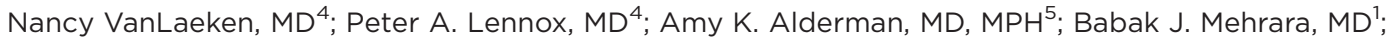

Joseph J. Disa, MD'; Peter G. Cordeiro, MD'; and Andrea L. Pusic, MD, MHS ${ }^{1}$

BACKGROUND. At a time when the safety and effectiveness of breast implants remains under close scrutiny, it is important to provide reliable and valid evidence regarding patient outcomes. In the setting of postmastectomy reconstruction, patient satisfaction and quality of life may be the most significant outcome variables when evaluating surgical success. The objective of the current study was to identify predictors of patient satisfaction with breast appearance, including implant type, in a large sample of women who underwent breast reconstruction surgery using implants. METHODS. A multicenter, cross-sectional study design was used. A total of 672 women who had completed postmastectomy, implant-based reconstruction at 1 of 3 centers in North America were asked to complete the BREAST-Q (Reconstruction Module). Multivariate linear regression modeling was performed. RESULTS. Completed questionnaire data were available for 482 of the 672 patients. In 176 women, silicone implants were placed and in 306, saline implants were used. The multivariate model confirmed that patients' satisfaction with their breasts was significantly higher in patients with silicone implants $(P=.016)$. The receipt of postmastectomy radiotherapy was found to have a significant, negative effect on breast satisfaction $(P<.000)$ in both silicone and saline implant recipients. In addition, for women who received either silicone or saline implants, satisfaction diminished over time $(P=$ .017). CONCLUSIONS. In the setting of postmastectomy reconstruction, patients who received silicone breast implants reported significantly higher satisfaction with the results of reconstruction than those who received saline implants. This information can be used to optimize shared medical decision-making by providing patients with realistic postoperative expectations. Cancer 2010;116:5584-91. (C) 2010 American Cancer Society.

KEYWORDS: breast surgery, mammoplasty, patient satisfaction, breast cancer, breast reconstruction, patientreported outcomes, saline, silicone, breast implants.

Although contemporary techniques provide numerous options for postmastectomy reconstruction, the majority of women will elect to pursue implant-based reconstruction. Currently, both saline and silicone gel implants are available for use. The recent decision by the US Food and Drug Administration (FDA) to approve the use of silicone breast implants in the United States has served to relieve concerns about their safety. However, the FDA has stipulated that ongoing surveillance of women who receive silicone implants be performed to monitor the efficacy of these devices. ${ }^{1}$

Women with breast cancer who elect to pursue mastectomy and implant-based reconstruction will be faced with the additional decision of which type of implant to choose. For these women and their care providers, including surgeons and medical oncologists, reliable outcome data must be considered to be an essential element of the informed decision-making process. The decision as to which permanent implant to choose should be made only after thoughtful consideration of the values the individual places on the possible benefits and risks.

Expert opinion suggests that reconstruction of the breast mound using a silicone gel implant generally allows for a softer, more natural-feeling breast with less visible and/or palpable wrinkling compared with saline-filled devices. ${ }^{2-4}$

Corresponding author: Colleen M. McCarthy, MD, MS, Memorial Sloan-Kettering Cancer Center, 1275 York Avenue, MRI 1007, New York, NY 10065; Fax: (212) 717-3677; mccarthc@mskcc.org

${ }^{1}$ Department of Surgery, Memorial Sloan-Kettering Cancer Center, New York, New York; ${ }^{2}$ Departments of Pediatrics and Clinical Epidemiology \& Biostatistics, McMaster University, Hamilton, Ontario, Canada; ${ }^{3}$ Brain Repair \& Rehabilitation, UCL Institute of Neurology, University College London, London, United Kingdom; ${ }^{4}$ Department of Surgery, University of British Columbia, Vancouver, British Columbia, Canada; ${ }^{5}$ Department of Surgery, University of Michigan, Ann Arbor, Michigan

DOI: 10.1002/cncr.25552, Received: February 19, 2010; Revised: May 4, 2010; Accepted: May 13, 2010, Published online November 8, 2010 in Wiley Online Library (wileyonlinelibrary.com) 
Although such surgeon-reported outcomes are noteworthy, the over-riding goal of postmastectomy reconstruction is to satisfy the patient with respect to the outcome. Thus, in the setting of postmastectomy reconstruction, the patient's perception of the results of surgery is 1 of the most important outcome variables and should be rigorously assessed in studies that attempt to evaluate surgical success.

Despite the growing awareness of patient-reported outcomes research, ${ }^{5-7}$ little is known concerning the patient characteristics that predict patient satisfaction with reconstruction. Therefore, the objective of the current study was to identify predictors of satisfaction with breast appearance, including implant type, in a large sample of women who underwent breast reconstruction surgery using implants.

\section{MATERIALS AND METHODS \\ Sample}

The patient sample for the current study was recruited over a 20-month period (February 2006 through September 2007) from the following surgical centers: Memorial Sloan-Kettering Cancer Center (MSKCC), New York, New York; University of Michigan, Ann Arbor, Michigan; and University of British Columbia, Vancouver, British Columbia, Canada. We included any woman aged $\geq 21$ years who had completed postmastectomy implant reconstruction 1 to 8 years previously and was unable to read English to complete a questionnaire booklet.

\section{Procedure}

A multicenter, cross-sectional study design was used. Institutional review board approval was obtained from each participating center. Patient electronic medical records were reviewed at the 3 participating centers to compile a list of eligible patients. Potential patients were assigned a study identification number and mailed a letter that described the study and a questionnaire booklet. The questionnaire contained the BREAST- $\mathrm{Q}^{8}$ and a series of items to collect data regarding patient demographics and clinical information. The questionnaire booklet was mailed along with a self-addressed, postage-paid return envelope. Methodology recommended by Dillman was used to maximize the questionnaire response rate; a reminder postcard was sent to participants within 3 weeks after the questionnaire mailing, after which up to 2 additional copies of the questionnaire were distributed as necessary.

\section{Questionnaire Booklet}

The BREAST-Q is a newly developed, patient-reported outcome measure (PROM) that was specifically designed to measure quality of life and patient satisfaction among breast surgery patients. ${ }^{8}$ The instrument was developed and validated with adherence to guidelines set by the Scientific Advisory Committee of the Medical Outcomes Trust (2002) and the US FDA. 6,10,11 The BREAST-Q Reconstruction Module's 15-item scale, "Satisfaction With Breasts," was used as the primary outcome measure in this current investigation. This scale addresses issues such as satisfaction with breast shape, feel to the touch, appearance, feelings of "normalcy," and integration of one's reconstructed breasts into self (Fig. 1). A Likert-type response format is used. The 15 items in the scale are summed and transformed on a scale of 0 to 100 , with higher values representing a more favorable outcome. Psychometric evaluation of the scale has shown high levels of internal consistency and test-retest reliability (Cronbach $\alpha, .96$; intraclass correlation coefficient, 0.96$){ }^{8}$

The questionnaire booklet also included individual items designed to collect both patient and treatment information. Patient information collected included age, marital status, employment, income, and ethnicity. Treatment information included implant type, length of time since surgery, timing of reconstruction (immediate vs delayed), laterality of reconstruction (bilateral vs unilateral), history of prior radiotherapy, and postmastectomy radiotherapy.

\section{Statistical Analysis}

We hypothesized that women who received silicone implants would report higher levels of satisfaction than those who received saline implants. Comparisons between saline and silicone implant recipients with respect to demographic and clinical variables were made using a Student $t$ test for continuous variables and a chi-square or Fisher exact test for categorical variables. To identify factors predictive of satisfaction with breasts, the relation between covariates and the "Satisfaction With Breasts" scale was assessed using linear regression models. Variables found to be significantly associated with patient satisfaction with their breasts at a $P$ value of. 10 on univariate analysis were included in the multivariate linear regression model using a stepwise selection procedure. The criterion to remain in the model was set to a $P$ value of.05. Cohen $d$ was used to quantify the effect size of variables related to "Satisfaction With Breasts" on the multivariate analysis. Cohen $d$ is defined as the difference between 2 means 
BREAST $-Q^{\text {TM }}$

RECONSTRUCTION MODULE (POST OPERATIVE) 1.0

\begin{tabular}{|c|c|c|c|c|c|}
\hline & & $\begin{array}{c}\text { Very } \\
\text { Dissatisfied }\end{array}$ & $\begin{array}{l}\text { Somewhat } \\
\text { Dissatisfied }\end{array}$ & $\begin{array}{l}\text { Somewhat } \\
\text { Satisfied }\end{array}$ & $\begin{array}{c}\text { Very } \\
\text { Satisfied }\end{array}$ \\
\hline a. & How you look in the mirror clothed? & 1 & 2 & 3 & 4 \\
\hline b. & $\begin{array}{l}\text { The shape of your reconstructed breast(s) when you are } \\
\text { wearing a bra? }\end{array}$ & 1 & 2 & 3 & 4 \\
\hline c. & How normal you feel in your clothes? & 1 & 2 & 3 & 4 \\
\hline d. & The size of your reconstructed breast(s)? & 1 & 2 & 3 & 4 \\
\hline e. & Being able to wear clothing that is more fitted? & 1 & 2 & 3 & 4 \\
\hline f. & How your breasts are lined up in relation to each other? & 1 & 2 & 3 & 4 \\
\hline g. & How comfortably your bras fit? & 1 & 2 & 3 & 4 \\
\hline h. & The softness of your reconstructed breast(s)? & 1 & 2 & 3 & 4 \\
\hline i. & How equal in size your breasts are to each other? & 1 & 2 & 3 & 4 \\
\hline j. & How natural your reconstructed breast(s) looks? & 1 & 2 & 3 & 4 \\
\hline k. & How naturally your reconstructed breast(s) sits/hangs? & 1 & 2 & 3 & 4 \\
\hline I. & How your reconstructed breast(s) feels to touch? & 1 & 2 & 3 & 4 \\
\hline $\mathrm{m}$. & $\begin{array}{l}\text { How much your reconstructed breast(s) feels like a } \\
\text { natural part of your body? }\end{array}$ & 1 & 2 & 3 & 4 \\
\hline $\mathrm{n}$. & How closely matched your breasts are to each other? & 1 & 2 & 3 & 4 \\
\hline o. & How you look in the mirror unclothed? & 1 & 2 & 3 & 4 \\
\hline
\end{tabular}

BREAST-Qm $\odot$ Memorial Sloan-Kettering Cancer Center and The University of British Columbia, 2006, All rights reserved

Figure 1. The BREAST-Q is a newly developed, patient-reported outcome measure that was specifically designed to measure quality of life and patient satisfaction among breast surgery patients.

divided by the pooled standard deviation for those means in which $<0.2$ is indicative of a "trivial" effect size, 0.2 to 0.5 indicates a "small" effect size, 0.5 to 0.8 indicates a "medium" effect size, and $>0.8$ indicates a "large" effect size. ${ }^{12-14}$ Stata statistical software was used (StataCorp, College Station, TX) and the $P$ value was set at.05. All $P$ values given are 2 -sided.

Data were collected by the research study assistants and processed in the departmental office of the lead institution (MSKCC). The lead author and biostatistician coauthors wrote the article, which was reviewed by all the authors, and vouch for the completeness and accuracy of the data presented.

\section{RESULTS}

A total of 672 women were sent a questionnaire booklet and completed questionnaires were received from 520 women (77\% response rate). We excluded from the analysis 38 respondents who either did not answer or indicated "not sure" with regard to the question asking them about their implant type. Of the remaining 482 patients, 176 had silicone implants and 306 had saline implants.

Table 1 shows patient characteristics for the saline implant and silicone implant groups. The 2 cohorts differed with respect to age (silicone patients were older), length of time since surgery (saline patients had longer follow-up), and the likelihood of having undergone bilateral 
Table 1. Demographic and Clinical Variables ( $n=482$ patients)

\begin{tabular}{|c|c|c|c|}
\hline Variable & $\begin{array}{l}\text { Saline Implant } \\
\text { Recipients }(n=306)\end{array}$ & $\begin{array}{l}\text { Silicone Implant } \\
\text { Recipients }(n=176)\end{array}$ & $P^{a}$ \\
\hline Mean age $( \pm S D), y$ & $51.3(10.4)$ & $53.7(11.0)$ & .017 \\
\hline Mean follow-up ( $\pm S D$ ), y & $3.3(2.0)$ & $2.4(1.9)$ & .000 \\
\hline $\begin{array}{l}\text { Timing of reconstruction } \\
\text { Immediate reconstruction } \\
\text { Delayed }\end{array}$ & $\begin{array}{r}227(74.2 \%) \\
79(25.8 \%)\end{array}$ & $\begin{array}{r}116(65.9 \%) \\
60(34.1 \%)\end{array}$ & NS \\
\hline $\begin{array}{l}\text { Laterality of reconstruction } \\
\text { Bilateral } \\
\text { Unilateral }\end{array}$ & $\begin{array}{l}122(39.9 \%) \\
184(60.1 \%)\end{array}$ & $\begin{array}{l}93(52.8 \%) \\
83(47.2 \%)\end{array}$ & .008 \\
\hline $\begin{array}{l}\text { History of prior radiotherapy } \\
\text { Yes } \\
\text { No }\end{array}$ & $\begin{array}{r}62(20.3 \%) \\
244(79.7 \%)\end{array}$ & $\begin{array}{r}44(25.0 \%) \\
132(75.0 \%)\end{array}$ & NS \\
\hline $\begin{array}{l}\text { Postmastectomy radiotherapy } \\
\text { Yes } \\
\text { No }\end{array}$ & $\begin{array}{r}59(19.3 \%) \\
247(80.7 \%)\end{array}$ & $\begin{array}{r}41(23.3 \%) \\
135(76.7 \%)\end{array}$ & NS \\
\hline $\begin{array}{l}\text { Marital status } \\
\text { Married/cohabitating with partner } \\
\text { Single/separated/widowed }\end{array}$ & $\begin{array}{r}80(26.1 \%) \\
226(73.9 \%)\end{array}$ & $\begin{array}{r}42(23.9 \%) \\
134(76.1 \%)\end{array}$ & NS \\
\hline $\begin{array}{l}\text { Highest level of education } \\
\text { High school } \\
\text { College, trade or university } \\
\text { Master/doctoral degree }\end{array}$ & $\begin{array}{r}39(13.0 \%) \\
174(58.2 \%) \\
86(28.8 \%)\end{array}$ & $\begin{array}{r}22(13.0 \%) \\
105(62.1 \%) \\
42(24.9 \%)\end{array}$ & NS \\
\hline $\begin{array}{l}\text { Employment } \\
\text { Employed } \\
\text { Homemaker/student/retired } \\
\text { Unable to work/seeking employment }\end{array}$ & $\begin{array}{l}176(59.9 \%) \\
97(33.0 \%) \\
21(7.1 \%)\end{array}$ & $\begin{array}{c}101(62.4 \%) \\
48(29.6 \%) \\
13(8.0 \%)\end{array}$ & NS \\
\hline $\begin{array}{l}\text { Ethnicity } \\
\text { Asian, East Indian, or Pacific Islander } \\
\text { Black non-Hispanic/black Hispanic } \\
\text { White non-Hispanic/white Hispanic } \\
\text { Native American/Native Canadian }\end{array}$ & $\begin{array}{c}12(4.0 \%) \\
12(4.0 \%) \\
267(87.8 \%) \\
13(4.2 \%)\end{array}$ & $\begin{aligned} & 3(1.7 \%) \\
& 2(1.1 \%) \\
161 & (92.0 \%) \\
9 & (5.2 \%)\end{aligned}$ & NS \\
\hline $\begin{array}{l}\text { Income } \\
\qquad \$ 40,000 \\
\quad \$ 40,000-\$ 80,000 \\
>\$ 80,000\end{array}$ & $\begin{array}{r}53(19.1 \%) \\
71(25.6 \%) \\
153(55.2 \%)\end{array}$ & $\begin{array}{l}22(13.0 \%) \\
51(30.2 \%) \\
96(56.8 \%)\end{array}$ & NS \\
\hline $\begin{array}{l}\text { Treatment center } \\
\text { A } \\
\text { B } \\
\text { C }\end{array}$ & $\begin{array}{r}101(33.0 \%) \\
167(54.6 \%) \\
38(12.4 \%)\end{array}$ & $\begin{array}{c}9 \text { (5.1\%) } \\
111(63.1 \%) \\
56(31.8 \%)\end{array}$ & .000 \\
\hline
\end{tabular}

SD indicates standard deviation; NS, not significant $(P>.05)$.

${ }^{a}$ Bold type indicates statistical significance.

versus unilateral reconstruction (bilateral reconstruction was performed more often in silicone implant recipients). In addition, the choice between saline versus silicone implants depended to some extent on the center at which the patient underwent their surgery.

Results of univariate analyses are presented in Table 2. Patient satisfaction with their breasts was greater in silicone implant versus saline implant recipients $(P=.004)$. After adjusting for patient age, length of follow-up, laterality, and medical center, the multivariate model identified 5 predictors of patient satisfaction with their breasts (Table 3). Specifically, women who reported more satisfaction with their breasts were more likely to report having silicone instead of saline implants $(P=.032)$, having undergone bilateral instead of unilateral reconstruction $(P \leq .001)$, having no history of prior radiotherapy $(P=.001)$, having no history 
Table 2. Univariate Analysis: Predicting Patient Satisfaction With Reconstructed Breasts

\begin{tabular}{|c|c|c|c|c|}
\hline \multicolumn{2}{|l|}{ Variable } & $\begin{array}{l}\text { No. OT } \\
\text { Patients }\end{array}$ & Scores ( $\pm S D)$ & $P^{\mathrm{a}, \mathrm{b}}$ \\
\hline \multirow[t]{2}{*}{ Type of implant } & Saline & 306 & $52.5 \pm 20.4$ & .004 \\
\hline & Silicone & 176 & $58.0 \pm 20.3$ & \\
\hline Length of follow-up, y & & 481 & - & .000 \\
\hline Age, y & & 478 & - & NS \\
\hline \multirow[t]{2}{*}{ Timing of reconstruction } & Immediate & 343 & $53.9 \pm 201$ & NS \\
\hline & Delayed & 131 & $55.6 \pm 20.1$ & \\
\hline \multirow[t]{2}{*}{ Laterality of reconstruction } & Unilateral & 267 & $51.1 \pm 21.6$ & .000 \\
\hline & Bilateral & 215 & $58.8 \pm 18.2$ & \\
\hline \multirow[t]{2}{*}{ Prior receipt of radiotherapy } & Yes & $106(22 \%)$ & $50.8 \pm 19.9$ & .034 \\
\hline & No & 376 (78\%) & $55.6 \pm 21.6$ & \\
\hline \multirow[t]{2}{*}{ Postmastectomy radiotherapy } & Yes & $100(20.7 \%)$ & $48.9 \pm 19.9$ & .002 \\
\hline & No & $382(79.3 \%)$ & $56.0 \pm 20.4$ & \\
\hline \multirow[t]{2}{*}{ Married/cohabitating } & Yes & $122(25.3 \%)$ & $53.7 \pm 20.8$ & NS \\
\hline & No & $360(74.7 \%)$ & $56.4 \pm 19.6$ & \\
\hline \multirow[t]{3}{*}{ Education $(n=468)$} & High school & 61 & $49.4 \pm 23.0$ & .098 \\
\hline & College/university & 280 & $55.9 \pm 21.0$ & \\
\hline & Master/doctoral & 129 & $54.1 \pm 17.7$ & \\
\hline \multirow{3}{*}{ Employment $(n=456)$} & Employed & 277 & $55.7 \pm 19.6$ & .051 \\
\hline & Homemaker/student & 145 & $51.4 \pm 21.0$ & \\
\hline & Unemployed & 34 & $53.3 \pm 23.9$ & \\
\hline \multirow[t]{4}{*}{ Ethnicity } & Asian & 15 & $52.5 \pm 10.7$ & NS \\
\hline & Black & 14 & $55.9 \pm 21.3$ & \\
\hline & White & 430 & $54.9 \pm 20.8$ & \\
\hline & Native American/Canadian & 22 & $47.9 \pm 20.5$ & \\
\hline \multirow[t]{3}{*}{ Income } & $<\$ 40,000$ & 75 & $40.1 \pm 21.7$ & .036 \\
\hline & $\$ 40,000-\$ 80,000$ & 122 & $55.1 \pm 20.8$ & \\
\hline & $>\$ 80,000$ & 249 & $55.7 \pm 19.5$ & \\
\hline \multirow[t]{3}{*}{ Treatment center } & A & 110 & $55.7 \pm 21.6$ & NS \\
\hline & B & 278 & $53.0 \pm 20.4$ & \\
\hline & C & 94 & $57.6 \pm 19.1$ & \\
\hline
\end{tabular}

SD indicates standard deviation; NS, not significant $(P>10)$.

${ }^{a}$ Bold type indicates statistical significance.

${ }^{b}$ Univariate analysis was performed using linear regression. Variables found to be significant at the.10 level were considered for entry into the multivariate model.

of postmastectomy radiotherapy $(P=.002)$, and for less time to have passed since having undergone surgery $(P=$ $.002)$. These 5 predictors combined to account for $10.5 \%$ of the variance in "Satisfaction With Breasts" scores (correlation coefficient $=0.105 ; P<.001$ ).

To estimate the clinical significance of the differences in patient satisfaction, effect sizes were computed (Table 4). Reconstruction with a silicone rather than a saline implant was found to be associated with an effect size of +0.27 ; bilateral reconstruction compared with unilateral reconstruction was found to be associated with an effect size of +0.35 ; and preoperative and postoperative radiotherapy were associated with effect sizes of -0.22 and -0.35 , respectively.

\section{DISCUSSION}

At a time when the safety and effectiveness of breast implants remains under close scrutiny, it is important to
Table 3. Multivariate Analysis: Patient Satisfaction With Reconstructed Breasts

\section{Variable}

Type of implant (silicone vs saline) Prior receipt of radiotherapy

Laterality of reconstruction

(bilateral vs unilateral)

Length of follow-up

Postmastectomy radiotherapy

\section{B Coefficient ${ }^{\mathrm{a}} \quad \boldsymbol{P}^{\mathrm{b}}$}

$\begin{array}{ll}4.1 & .032 \\ -8.1 & .001 \\ 6.3 & .001\end{array}$

$-1.4-.002$

$-8.9 \quad .002$
${ }^{a}$ Beta coefficient was derived from the multivariate model, after adjustment by all relevant variables. Positive values indicate more satisfaction and negative values indicate less satisfaction.

${ }^{\mathrm{b}}$ Bold type indicates statistical significance.

examine surgical effectiveness. In the field of breast reconstruction, surgery is directed toward a restoration or improvement in the appearance of the breasts as perceived by the patient. Thus, in the setting of postmastectomy 
Table 4. Effect of Treatment Variables on Patient Satisfaction With Reconstructed Breasts: Determination of Effect Size (Cohen $d$ )

\section{Silicone Implant Recipients (Mean Score \pm SD)}

$58.0 \pm 20.3$

Bilateral Implant Recipients

(Mean Score \pm SD)

$58.8 \pm 18.3$

Recipients of Postoperative

Radiotherapy (Mean Score \pm SD)

$48.9 \pm 19.9$

Recipients of Preoperative

Radiotherapy (Mean Score \pm SD)

$50.8 \pm 19.9$

\section{Saline Implant Recipients (Mean Score \pm SD)}

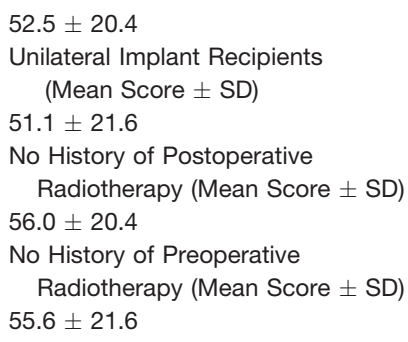

\section{Difference Between Mean Group Scores}

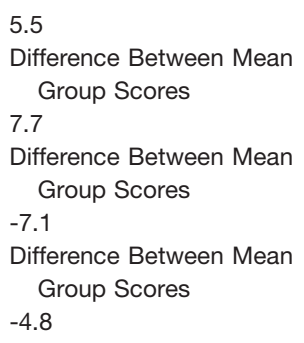

\section{Effect Size (Cohen d)}

0.27

Effect Size (Cohen $d$ )

0.35

Effect Size (Cohen $d$ )

$-0.35$

Effect Size (Cohen $d$ )

$-0.22$

$\mathrm{SD}$ indicates standard deviation.

reconstruction, the assessment of outcomes such as patient satisfaction is especially important because these outcomes are the predominant determinants of success. The current study identified 5 predictors of patient satisfaction. Perhaps of most interest to patients and surgeons is our finding that patient satisfaction with the results of breast reconstruction was higher among those who received silicone implants compared with those who received saline implants.

Numerous studies have confirmed the positive psychological effects of breast reconstruction. ${ }^{15-18}$ However, to the best our knowledge, there are a paucity of data examining the interaction between specific treatment variables and patient satisfaction with reconstruction. Different authors have considered the impact of implant versus autogenous tissue techniques and of immediate versus delayed reconstruction. ${ }^{19-22}$ However, to our knowledge, few have attempted to evaluate the effect of more subtle treatment considerations, such as implant type, on patients' perceptions of outcome.

Handel et al attempted to evaluate the degree of patient satisfaction in silicone versus saline implant recipients. ${ }^{23}$ Patients who had a history of prior cosmetic augmentation and/or postmastectomy reconstruction were asked to complete an ad hoc (nonvalidated) questionnaire. Of the 853 patients administered the questionnaire, 429 (approximately 50\%) responded. On the basis of the results, the authors concluded that patient satisfaction was not influenced by type of implant filler material received.

Without the use of an appropriate PROM, the results of this aforementioned investigation are considerably less meaningful. For example, if the questionnaire used cannot be shown to measure what it is intended to measure in a consistent and reproducible fashion, then the conclusions drawn cannot claim to be reliable or valid. Furthermore, such an instrument may not be sensitive enough to detect differences between patient groups. In contrast, the use of a reliable, valid, and responsive PROM (the BREAST-Q) in the current study enabled us to capture essential information regarding the impact and effectiveness of silicone breast implants in the setting of postmastectomy reconstruction. On the basis of our findings, it appears that patients who received silicone breast implants experienced higher satisfaction with their reconstruction compared with those who received saline implants.

It is important to interpret these findings not based solely on their statistical significance, but also in light of their clinical significance. The effect size for all predictors of a patient's satisfaction with their breasts was small, which likely reflects the findings that patient satisfaction after reconstruction is generally high and that individual treatment variables explain only a relatively small amount of the variance noted. Patient counseling should reflect these realities to reassure patients that high satisfaction may be obtained with both saline and silicone implants.

However, in the context of shared medical decisionmaking, patients seek meaningful data with which to make an informed choice regarding their implant type. The results of the current study suggest that patients may expect higher satisfaction by electing to have a permanent silicone rather than a saline implant. It is important, however, for physicians and patients alike to understand the magnitude of this effect and put it in the context of the impact of other treatment variables.

It is interesting to note that it appears that the magnitude of the positive effect of silicone implants on patient 
satisfaction is similar to the size of the negative effect of radiotherapy. Our finding, which suggests that both preoperative and postoperative radiotherapy are important predictors of patient satisfaction, is consistent with other published reports. Numerous studies have shown that patients who undergo postmastectomy, implant-based reconstruction after the receipt of preoperative chest wall irradiation have a higher incidence of complications, including capsular contracture, ${ }^{19,24-26}$ and that the receipt of postmastectomy adjuvant radiotherapy is correlated with both the development of complications and increased patient dissatisfaction. ${ }^{27-30}$ Thus, the determination of effect size herein allowed clinically meaningful comparisons to be made between the effects of a known entity (such as postmastectomy radiotherapy) versus other clinical variables (such as implant type) that may have an impact on patients' satisfaction with their reconstructed breasts.

The results of the current study also suggest that the magnitude of the positive effect the receipt of silicone implants has on patient satisfaction is similar to the magnitude of the positive impact of the receipt of bilateral reconstruction. In the context of implant breast reconstruction, an advantage of bilateral breast reconstruction is that a patient's reconstructed breast need not match a contralateral, native breast, but rather a contralateral, reconstructed breast. Thus, it is hypothesized that symmetry with respect to breast size and shape may be superior in patients with bilateral reconstructions and may, in turn, influence a patient's perception of outcome.

Finally, the current study data suggest that time since the completion of reconstruction has a negative impact on a patient's satisfaction with their reconstructed breasts. These results are consistent with those published by Gui et al, who reported that a greater percentage of women reported dissatisfaction with their reconstructed breasts at 6 years after reconstruction compared with at 1 year. ${ }^{31}$ Clough et al similarly reported a deterioration in esthetic outcome in the first 5 years after immediate, implant-based breast reconstruction. ${ }^{32}$ Factors such as the development of scar tissue or capsular contracture around an implant are likely to be significant in influencing longterm outcome after breast reconstruction.

The strengths of the current study include its multicenter nature; a high response rate; and the use of a valid and reliable, surgery-specific PROM. However, a central limitation of the current study is the lack of reliable clinical data regarding the specific types of silicone implants used, the development of postoperative complications (ie, capsular contracture), and additional procedures performed (ie, contralateral matching procedure and/or revisional procedures). Future studies evaluating the impact of these variables on patients' perceptions of outcome are thus warranted.

\section{Conclusions}

The results of the current study suggest that patients who receive silicone breast implants report higher satisfaction with the results of reconstruction compared with those who receive saline implants. This information can be used to optimize shared medical decision-making by providing breast cancer survivors with a more accurate estimation of predicted outcomes and more individualized treatment choices. These findings will also support advocacy efforts, providing policy makers with reliable, patient-reported outcome data regarding the effectiveness of saline and silicone implant breast reconstruction.

\section{CONFLICT OF INTEREST DISCLOSURES}

The authors made no disclosures.

\section{REFERENCES}

1. US Food and Drug Administration. FDA Approves Silicone Gel-Filled Breast Implants After In-Depth Evaluation. Washington, DC: US Food and Drug Administration; 2006. Available at: http://www.fda.gov/bbs/topics/NEWS/ 2006/NEW01512.html. Accessed May 11, 2009.

2. Rohrich RJ, Reece EM. Breast augmentation today: saline versus silicone-what are the facts? Plast Reconstr Surg. 2008; 121:669-672.

3. Brown MH, Shenker R, Silver SA. Cohesive silicone gel breast implants in aesthetic and reconstructive breast surgery. Plast Reconstr Surg. 2005;116:768-779.; discussion 780-781.

4. Cordeiro PG. Breast reconstruction after surgery for breast cancer. $N$ Engl J Med. 2008;359:1590-1601.

5. European Medicines Agency. Reflection Paper on the Regulatory Guidance for the Use of the Health-Related Quality of Life (HRQL) Measures in the Evaluation of Medicinal Products. London, UK: European Medicines Agency; 2008. Available at: http://www.emea.europa.eu/pdfs/human/ewp/ 13939104en.pdf. Accessed May 11, 2009.

6. US Food and Drug Administration. Patient-Reported Outcome Measures: Use in Medical Product Development to Support Labeling Claims. Washington, DC: US Food and Drug Administration; 2006. Available at: http://www.fda. gov/CDER/GUIDANCE/5460dft.pdf. Accessed May 11, 2009.

7. Revicki DA. FDA draft guidance and health-outcomes research. Lancet. 2007;369:540-542.

8. Pusic AL, Klassen AF, Scott AM, Klok JA, Cordeiro PG, Cano SJ. Development of a new patient-reported outcome measure for breast surgery: the Breast-Q. Plast Reconstr Surg. 2009; 124:345-353. 
9. Dillman DA. Mail and Internet Surveys. The Tailored Design Method. 2nd ed. Toronto: John Wiley \& Sons Inc; 2000.

10. Nissen MJ, Swenson KK, Kind EA. Quality of life after postmastectomy breast reconstruction. Oncol Nurs Forum. 2002;29:547-553.

11. [no authors listed]. Assessing health status and quality-of-life instruments: attributes and review criteria. Qual Life Res. 2002;11:193-205.

12. Cohen J.Statistical Power Analysis for the Behavioral Sciences. 2nd ed. Hillsdale, NJ: Lawrence Earlbaum Associates; 1988.

13. Cohen J. A power primer. Psychol Bull. 1992;112:155-159.

14. Aaron B, Kromrey JD, Ferron JM. Equating r-Based and dBased Effect-Size Indices: Problems With a Commonly Recommended Formula. Presented at: Florida Educational Research Association; November 2-4, 1998; Orlando, Florida.

15. Schain WS, Wellisch DK, Pasnau RO, Landsverk J. The sooner the better: a study of psychological factors in woman undergoing immediate versus delayed breast reconstruction. Am J Psychiatry. 1985;142:40-46.

16. Dean C, Chetty U, Forrest AP. Effects of immediate breast reconstruction on psychosocial morbidity after mastectomy. Lancet. 1983;1:459-462.

17. Andrade WN, Baxter N, Semple JL. Clinical determinants of patient satisfaction with breast reconstruction. Plast Reconstr Surg. 2001;107:46-54.

18. Pusic A, Thompson TA, Kerrigan CL, et al. Surgical options for the early-stage breast cancer: factors associated with patient choice and postoperative quality of life. Plast Reconstr Surg. 1999;104:1325-1333.

19. Alderman AK, Wilkins EG, Lowery JC, Kim M, Davis JA. Determinants of patient satisfaction in postmastectomy breast reconstruction. Plast Reconstr Surg. 2000;106:769-776.

20. Alderman AK, Kuhn LE, Lowery JC, Wilkins EG. Does patient satisfaction with breast reconstruction change over time? Two-year results of the Michigan Breast Reconstruction Outcomes Study. J Am Coll Surg. 2007;204:7-12.

21. Cederna PS, Yates WR, Chang P, Cram AE, Ricciardelli EJ. Postmastectomy reconstruction: comparative analysis of the psychosocial, functional, and cosmetic effects of transverse rectus abdominis musculocutaneous flap versus breast implant reconstruction. Ann Plast Surg. 1995;35:458-468.
22. Edsander-Nord A, Brandberg Y, Wickman M. Quality of life, patients' satisfaction, and aesthetic outcome after pedicled or free TRAM flap breast surgery. Plast Reconstr Surg. 2001;107:1142-1153.

23. Handel N, Cordray T, Gutierrez J, Jensen JA. A long-term study of outcomes, complications, and patient satisfaction with breast implants. Plast Reconstr Surg. 2006;117:757-767.

24. Ascherman JA, Hanasono MM, Newman MI, Hughes DB. Implant reconstruction in breast cancer patients treated with radiation therapy. Plast Reconstr Surg. 2006;117:359-365.

25. Spear SL, Onyewu C. Staged breast reconstruction with saline-filled implants in the irradiated breast: recent trends and therapeutic implications. Plast Reconstr Surg. 2000;105:930-942.

26. Krueger EA, Wilkins EG, Strawderman M, et al. Complications and patient satisfaction following expander/implant breast reconstruction with and without radiotherapy. Int $J$ Radiat Oncol Biol Phys. 2001;49:713-721.

27. Shaikh-Naidu N, Preminger BA, Rogers K, Messina P, Gayle LB. Determinants of aesthetic satisfaction following TRAM and implant breast reconstruction. Ann Plast Surg. 2004;52:465-470; discussion 470.

28. Cordeiro PG, Pusic AL, Disa JJ, McCormick B, VanZee K. Irradiation after immediate tissue expander/implant breast reconstruction: outcomes, complications, aesthetic results, and satisfaction among 156 patients. Plast Reconstr Surg. 2004;113:877-881.

29. Olsen MA, Lefta M, Dietz JR, et al. Risk factors for surgical site infection after major breast operation. J Am Coll Surg. 2008;207:326-335.

30. Jhaveri JD, Rush SC, Kostroff K, et al. Clinical outcomes of postmastectomy radiation therapy after immediate breast reconstruction. Int J Radiat Oncol Biol Phys. 2008;72:859865.

31. Gui GP, Kadayaprath G, Tan SM, et al. Long-term qualityof-life assessment following one-stage immediate breast reconstruction using biodimensional expander implants: the patient's perspective. Plast Reconstr Surg. 2008;121:17-24.

32. Clough KB, O’Donoghue JM, Fitoussi AD, Nos C, Falcou MC. Prospective evaluation of late cosmetic results following breast reconstruction: I. Implant reconstruction. Plast Reconstr Surg. 2001;107:1702-1709. 